\title{
Bilingualism and Creative Abilities in Early Childhood
}

\author{
Mark Leikin ${ }^{1}$, Esther Tovli ${ }^{2} \&$ Sergey Malykh ${ }^{3}$ \\ ${ }^{1}$ Department of Special Education, Laboratory for Neurocognitive Examination of Giftedness, University of Haifa, \\ Israel \\ ${ }^{2}$ Shaanan College, Haifa, Israel \\ ${ }^{3}$ The Academic Institute of Psychology, Moscow, Russian Federation \\ Correspondence: Prof. Mark Leikin, Head of the Laboratory for Neurocognitive Examination of Giftedness, Faculty \\ of Education, University of Haifa, Haifa 31905, Israel. Fax: 972-04-8240911. E-mail: mark1@edu.haifa.ac.il
}

Received: September 17, 2014

Accepted: October 5, 2014

Online Published: October 9, 2014

doi:10.5430/elr.v3n2p54

URL: http://dx.doi.org/10.5430/elr.v3n2p54

\begin{abstract}
The present study was motivated by a scarcity of knowledge about the impact of early bilingualism on the development of general creativity and mathematical creativity. Two groups of bilingual and monolingual preschoolers (mean age $=60.9$ months, $\mathrm{SD}=3.1$ ) from the same monolingual kindergarten participated in this study: 15 Russian/Hebrew balanced bilinguals and 15 native Hebrew-speaking monolinguals. All children were administered the Figural Form A (Thinking Creatively with Pictures) from the Torrance Tests of Creative Thinking, the Pictorial Multiple Solution Task assessing general creativity, and the Creating Equal Number task measuring mathematical creativity. Bilingual children showed higher creative ability than their monolingual peers. It seems, however, that bilingualism affects various domains of creative ability differently. Consistent with findings of an earlier study (M. Leikin, 2013) the results demonstrate that relationships between creativity components and bilingualism are task dependent, and when differences between bilingual and monolingual children are revealed, they are in favor of bilinguals. In other words, advantages in creative ability in bilinguals are specific rather than general.
\end{abstract}

Keywords: Bilingualism, Early childhood, General and mathematical creativity

The present study was motivated by a scarcity of knowledge about the impact of early bilingualism on the development of creativity, especially with regard to the cognitive mechanisms involved. Studies conducted in the last decade show that bilingualism has a strong influence not only on the development of language ability and linguistic skills but on cognitive development as well (Bialystok, 2009; Kroll, Dussias, Bogulski, \& Kroff, 2012).

The advantages of bilingualism have been reported across a variety of domains, including a wide range of executive functions (e.g., in inhibition, cognitive flexibility, and updating of working memory - see, for example, Kroll et al., 2012; Hommel, Clozato, Fscher, \& Christtofels, 2011; Prior \& MacWhinney, 2010), problem-solving (Adesope, Lavin, Thompson, \& Ungerleider, 2010; Bialystok, 2009), and creativity (mostly expressed in divergent thinking or cognitive flexibility) (Adi-Japha, Berberich-Artzi \& Libnawi, 2010; Hommel et al., 2011; M. Leikin, 2013; Kharkhurin, 2010a, 2012; Ricciardelli, 1992b; Simonton, 2008). It has also been found that the performance of balanced bilingual individuals is better than that of their non-balanced peers (Cummins, 1976, 2000; M. Leikin, 2013). Note, however, that most research in the field of creativity has focused primarily on language creativity and on school-age children, adolescents, and adults, whereas the creative abilities of younger bilingual preschool children have not been studied adequately (M. Leikin, 2013; Kharkhurin, 2012; Ricciardelli, 1992a; Simonton, 2008).

Despite numerous attempts to define creativity, no agreement has been reached on the subject. First of all, it is not clear whether the term "creativity" refers to people's abilities or inclinations, their behavior or actions, or to the result of some form of human activity (e.g., Barron \& Harrington, 1981; Hommel et al., 2011). For example, creativity is usually considered to be a mental process involving the generation of new ideas or new connections between existing ideas or concepts (see Simonton, 2000 for a review). Creativity can also be manifested in the production of creative outcomes that are both original and useful (Simonton, 2008; Saul \& Leikin, 2010). An alternative and more common conception of creativity suggests that it is simply the act of making something new and different from what others are making (cf. "relative creativity," R. Leikin, 2009, 2013). An additional difficulty in the definition of creativity 
has to do with possible differences between levels of complexity of the problem to be solved or between degrees of elegance of the solution. In this case, the type of problem (verbal, figurative, mathematical, etc.) also seems to play an important role (Barron \& Harrington, 1981; Heilman, 2005; M. Leikin, 2013; Simonton, 2008).

In the present study we investigated figurative (non-verbal) creativity (Torrance Tests of Creative Thinking - TTCT) and creativity in solving situational (everyday or general) and mathematical problems. In TTCT the standard procedure of analysis of Torrance (1974) was used. In other tests we use R. Leikin's $(2009,2013)$ model for the evaluation of mathematical creativity based on solving Multiple Solution Tasks (MSTs), which are assignments that explicitly require the solver to approach a mathematical problem in different ways (see also R. Leikin, 2013). This model is based on a definition of creativity by Torrance (1974), who suggests four mutually related components: fluency, flexibility, novelty, and elaboration (see also Simonton, 2000, 2008). In this case, fluency relates to the continuity of ideas and use of basic and universal knowledge. Flexibility is associated with changing ideas, approaching a problem in various ways, and producing a variety of solutions (cf. notion of convergent thinking, Runco, 2008). Novelty (or originality) is characterized by a unique way of thinking and by unique products of a mental or artistic activity, and elaboration relates to the ability to describe, illuminate, and generalize ideas.

R. Leikin $(2009,2013)$ suggested a scoring scheme for the evaluation of mathematical creativity that combines the fluency, flexibility, and originality of the solutions produced by the solver. This method has been shown to be suitable not only for mathematics but also for the evaluation of creativity in the solving of non-mathematical problems (M. Leikin, 2013; M. Leikin \& Tovli, in press).

\section{Bilingualism and Creativity}

The literature generally supports the hypothesis that positive correlations exist between bilingualism an creativity (Adesope et al., 2010, Kharkhurin, 2012; Ricciardelli, 1992a; Simonton, 2008). For example, it was found (Simonton, 2008) that bilinguals scored higher than monolinguals on both verbal and figural originality and flexibility. Note, however, that recently Kharkhurin (2010a) found significant differences between nonverbal and verbal creativity in a bilingual context. Bilingualism was shown to have a positive effect on nonverbal creative behavior; however, monolinguals were found to be better than bilinguals on verbal creativity measures. These data at least partly contradict the results of Cummins's studies $(1976,2000)$, which found that balanced bilinguals achieved higher scores on the fluency and flexibility scales of verbal divergence and marginally higher scores on the originality scale than did matched non-balanced bilinguals. Mostly similar results were shown also by M. Leikin and Tovli (in press).

Simonton (2008) identified several important methodological and theoretical factors that should be taken into account when considering the mutual relationship between bilingualism and creativity. On the one hand, there is no doubt that creativity is a complex cognitive phenomenon, often correlating with IQ. On the other hand, bilingualism is also a complex concept. Therefore, the relationship between creativity and bilingualism may be affected by a variety of additional factors such as cultural features, age, and the type of bilingualism. In his review Simonton (2008) noted that there are positive correlations between creativity and proficiency in two languages, e.g., differences between fluent (balanced) and non-fluent bilinguals (see also Adesope et al., 2010; M. Leikin, 2013; Ricciardelli, 1992a, 1992b).

To date, little research has been devoted to the investigation of the relationship between bilingualism and bilingual development, on the one hand, and creative thinking or creativity in problem solving on the other. Moreover, there are few studies on preschool children in this respect (e.g., Adi-Japha et al., 2010; M. Leikin, 2013; see also Kharkhurin, 2012; Ricciardelli, 1992a; Simonton, 2008). A review of the research literature in the field did not reveal any studies that compare figurative and general creativity with mathematical creativity in young balanced bilinguals. Accordingly, in this study we examined the abovementioned issue in older preschoolers with well-developed Russian/Hebrew bilingualism.

\section{Research goals and hypothesis}

The first aim of the present study was to check whether early bilingualism affects the development of creativity. This aim led to the following hypothesis: If bilingualism has a positive effect on creative ability, bilingual children will demonstrate better results on creativity tests than will monolingual children of the same age and socio-economic group.

The second aim of the study was to examine the possible effects of bilingualism on figural creativity and creativity in non-mathematical and mathematical problem solving of bilingual preschoolers compared with their monolingual peers. Based on the research data on creative behavior in different cognitive fields (e.g., language and non-language 
creativity) and on our previous findings (M. Leikin, 2013; M. Leikin \& Tovli, in press), we hypothesized that there is no unequivocal correlation between different types of creativity.

\section{Method}

\subsection{Participants}

Thirty children (mean age $=60.9$ months, $\mathrm{SD}=3.1$ ) were selected from two Hebrew-speaking monolingual kindergartens in northern Israel. The children were divided into two groups (Table 1):

1. Bilingual (Russian/Hebrew-speaking) children from Russian-speaking immigrant families (henceforth the bilinguals, $\mathrm{n}=15$ );

2. Monolingual (Hebrew-speaking) children from the same monolingual kindergartens as the bilingual group (henceforth the monolinguals, $\mathrm{n}=15$ ).

Table 1. Means and standard deviations of background measures for monolingual and bilingual participants

\begin{tabular}{|c|c|c|c|c|c|}
\hline & Monolinguals & Bilinguals & $p$ & $\chi^{2}$ & $\eta^{2}$ \\
\hline Gender (male/ female) & $7 / 8$ & $6 / 9$ & & .136 & \\
\hline Age (in months) & $61.3(2.8)$ & $60.5(3.4)$ & .484 & & .018 \\
\hline Mother's age (in years) & $35.8(4.7)$ & $34.8(4.6)$ & .560 & & .012 \\
\hline Mother's residence in Israel (in years) & & $17.7(4.8)$ & & & \\
\hline Mother's education (in years) & $13.8(1.7)$ & $12.5(2.1)$ & .069 & & .113 \\
\hline Father's age (in years) & $39.4(8.0)$ & $37.3(4.8)$ & .385 & & .027 \\
\hline Father's residence in Israel (in years) & & $17.8(4.4)$ & & & \\
\hline Father's education (in years) & $12.5(1.3)$ & $13.1(2.3)$ & 391 & & .026 \\
\hline
\end{tabular}

The two Hebrew-speaking kindergartens were located in similar neighborhoods with an average socio-economic level. The kindergarten teachers in the two target programs used the same curriculum provided by the Israeli Ministry of Education.

The classification of children as monolingual or bilingual was based on a detailed questionnaire (M. Leikin, 2013) that collected information about the native language of the child's parents, the language spoken at home and by the preschool teachers and caregivers. The bilinguals were Israeli-born children of Russian-speaking immigrants from the former USSR. Russian was the dominant language in the homes of all these children. At the same time, the children had already acquired Hebrew at a level that was almost equivalent to that of their monolingual peers. According to the general impressions (speech fluency, syntax, and vocabulary and spoken language comprehension measured in 1 to 10 scales) of three Russian/Hebrew-speaking raters $(\alpha=.893)$ and according to data obtained from family questionnaires, the children knew Russian sufficiently well to understand movies, TV shows, and Russian language books read to them by adults, and were able to converse and express their thoughts in Russian at a level comparable to Hebrew. At the same time, three native Hebrew-speaking raters characterized the children's linguistic competence in Hebrew as nearly the same as that of their Hebrew-speaking coevals $(\alpha=.921)$.

There were no significant differences between the two groups of participants in mean age, gender, and the parents' educational level (see Table 1 for details). An average time of residence in Israel for families of bilingual children was about 17.5 years $(M=17.7 S \mathrm{D}=4.8$ and $M=17.8, S D=4.4$ for mothers and fathers, respectively).

\subsection{Measures}

\subsubsection{Creative thinking tests}

I. Figural Form A (Thinking Creatively with Pictures) of the TTCT - Torrance Tests of Creative Thinking (Torrance, 1974). The test consists of the following three 10-minute tasks or activities: Picture Construction, Picture Completion, and Repeated Figures (Parallel Lines). According to Torrance (1974), two dimensions of divergent thinking (originality and elaboration) are measured for the first task, and four - for the two other tasks (fluency, flexibility, originality, and elaboration). In this case, the fluency measure refers to the number of different ideas one can produce; flexibility refers to the variety of ideas one produces; originality refers to how unusual the ideas one produces; and elaboration refers to richness of detail in the ideas one produces (Prieto, Parra, Ferrándo, Ferrándiz, Bermejo, \& Sánchez, 2006; Torrance, 1974). 


\section{Pictorial Multiple Solution (PMS) Task (M. Leikin, 2013)}

In a black-and-white picture (see Appendix 1), a small childlike kitten, easily associated as a coeval of the young study participants, wants to reach its cap on a high shelf but is unable to do so. There are various objects in the picture that could be used to help the kitten reach its cap: a chair, a stool, a bedside table, and a stick. Participants were asked to suggest as many solutions as they could to the problem presented in the picture. Each answer was scored for fluency, flexibility, originality, and creativity by using R. Leikin's (2009) model for the evaluation of mathematical creativity based on solving Multiple Solution Tasks (MSTs), assignments that explicitly require the solver to approach a mathematical problem in different ways (see also M. Leikin, 2013). This model is based on Torrance's (1974) definition of creativity.

The fluency score was obtained by counting the number of solutions provided by the participant. To evaluate flexibility, groups of solutions were established in such a way that two solutions belonged to separate groups if they employed solution strategies based on different principles, properties, or methods for problem-solving. For example, "get a stick," "jump up," and "call mom" are decisions belonging to different groups, whereas "climb on the chair," "climb on the table," and "climb on a ladder" belong to the same group. The children received a score of 10 for the first appropriate solution $\left(\mathrm{Flx}_{1}\right)$ belonging to a group other than $\mathrm{Flx}_{1}$. The children received a score of 1 for a solution $\left(\mathrm{Flx}_{\mathfrak{i}}\right)$ belonging to one of the previously used groups and having a clear but minor distinction (e.g., "climb on a ladder" vs. "to climb on the chair"). Finally, the children received a score of 0.1 for a solution that was almost identical to a previous one. A participant's total flexibility score was the sum of the flexibility scores of the solutions in the participant's individual solution space. The originality (Ori) score was also calculated based on a preliminary classification of solutions. In this case, however, all the answers of all the participants in the experiment were analyzed together and each solution received a corresponding individual score: Ori $=10$ when a given solution was suggested by fewer than $15 \%$ of all participants, Ori $=1$ when a given solution was suggested by more than $15 \%$ but fewer than $40 \%$ of participants, and Ori $=0.1$ when a given solution was suggested by more than $40 \%$ of participants. A participant's total originality score on a problem was the sum of originality scores of all the solutions in the expert solution space (all solutions of all participants).

The creativity score was calculated by multiplying the flexibility score of each solution by its originality score, then adding up the results of the creativity scores obtained for all the solutions by the participant (for details, see R. Leikin, 2009, 2013). The R. Leikin's (2009) scoring scheme does not include fluency scores due to the high correlation between fluency and flexibility scores. In this case, the flexibility measure was found to be more accurate than the one for fluency, and it was proven (R. Leikin, 2009) that the final creativity scores did not depend significantly on whether or not the resulting formula for creativity scoring included fluency scores.

III. Creating Equal Number (CEN) Task (based on Tsamir, Tirosh, Tabach, \& Levenson, 2009)

In the present study we used a slightly modified CEN task. Unlike the original test (Tsamir et al., 2009), in the present test the children were asked to use 10 bottle caps, instead of 8 , in order to yield a greater variety of solutions in problem solving. The child was presented with two distinct sets of bottle caps: three bottle caps were placed on one side of the table and seven caps were placed on the other side. No spare bottle caps were present. All bottle caps had the same shape, size, and color. The child was asked: 'Can you make it so that there will be an equal number of bottle caps on each side of the table?' After the child rearranged the bottle caps, the interviewer returned the caps to their original arrangement and asked the child, 'Is there another way of making the number of bottle caps on each side equal?' This task was repeated until the child signaled that he or she had finished (Tsamir et al., 2009).

Fluency, flexibility, originality, and creativity scores were calculated in the same way as in the previous test. In this case, however, we considered not only the children's solutions (outcomes) but also the ways in which the problem was solved. The CEN task can have six different solutions: 5-5, i.e., five caps in each set, 4-4, 3-3, 2-2, 1-1, and 0-0. Additionally, there are several methods to solve the problem. Some are one-step methods: (a) removing all the elements from both sets, leading to an outcome of $0-0$; (b) taking four elements from the set of seven, producing a solution of 3-3; (c) shifting from one set to the other, which led to a solution of 5-5; (d) taking from both sets a number of elements to obtain the same number of caps in each set, leading to solutions of 1-1 or 2-2. A two-step method (e) involved collecting all the caps and re-dividing them to create two new sets from scratch. This method could result in any of the six above-mentioned solutions. Finally, another two-step method (f) involved removing three elements from the larger set with a partial addition of 1 element to the smaller group. This method produced a result of 4-4.

The first appearance of any solution (i.e., the first-time use of a method) received a score of 10 on flexibility, and all others in which the same method of solving the problem was applied, received a score of 0.1 . An exception was 
made for an outcome of $0-0$, which was considered to be rare and especially interesting. Thus, on the originality measure, all outcomes, produced by any method, received a score that depended on the percentage of children who used that solution.

All tests were conducted in Hebrew by a native Hebrew-speaking examiner.

\section{Results}

\subsection{Background measures}

Table 1 presents the children's background data. A series of one-way analyses of variance (ANOVA) were conducted to evaluate the differences between the two groups of participants on the background measures. The results presented in Table 1 show that the experimental groups did not differ significantly in the children's gender and age or in the age and education level of their parents.

\subsection{Experimental measures}

\subsubsection{Figural TTCT: Thinking Creatively with Pictures}

The results of participants' performance on the TTST (figural) are presented in Table 2. A series of one-way analyses of variance (ANOVA) were conducted to evaluate the differences between monolingual and bilingual children performance.

Table 2. Children's performance on the TTCT ( $M$ and $S D$ )

\begin{tabular}{lcccc}
\hline & Monolinguals & Bilinguals & $p$ & $\eta^{2}$ \\
\hline TTCT picture construction & & & & .363 \\
$\quad$ Originality & $2.7(1.8)$ & $3.3(1.8)$ & .030 \\
$\quad$ Elaboration & $9.7(8.4)$ & $11.9(5.7)$ & $.044^{*}$ & .137 \\
TTCT picture completion & & & & \\
$\quad$ Fluency & $9.1(1.3)$ & $10.00(.00)$ & $.012^{*}$ & .206 \\
Flexibility & $7.3(1.7)$ & $7.6(1.2)$ & .624 & .009 \\
Originality & $11.3(4.2)$ & $13.1(2.5)$ & .160 & .069 \\
$\quad$ Elaboration & $13.1(13.7)$ & $13.5(14.8)$ & .787 & .003 \\
TTCT repeated figures of lines & & & & \\
$\quad$ Fluency & $9.0(4.0)$ & $12.3(4.9)$ & $.049^{*}$ & .139 \\
$\quad$ Flexibility & $6.9(3.7)$ & $10.9(3.5)$ & $.005^{* *}$ & .251 \\
$\quad$ Originality & $14.7(7.3)$ & $21.4(8.2)$ & $.025^{*}$ & .166 \\
$\quad$ Elaboration & $12.7(13.5)$ & $13.7(18.3)$ & .134 & .078 \\
Total Fluency & $18.1(13.4)$ & $22.3(12.9)$ & $.024^{*}$ & .168 \\
Total Flexibility & $14.2(5.1)$ & $18.5(3.6)$ & $.012^{*}$ & .204 \\
Total Originality & $28.7(9.8)$ & $37.8(9.5)$ & $.015^{*}$ & .193 \\
Total Elaboration & $35.5(19.2)$ & $38.2(18.1)$ & .231 & .051 \\
\hline
\end{tabular}

$* p \leq .05,{ }^{* *} p \leq .01$

Inspection of Table 2 shows that there were significant differences between two participant groups (in favor of the bilingual children) in total scores of fluency, flexibility and originality but not in elaboration. Considering specifically three subtests of Figural TTST note that in the Picture Construction task bilinguals marginally differed from monolinguals only in the elaboration measure. Also in the Picture Completion task significant differences were obtained only in one measure, i.e. in fluency. On the contrary, in the Repeated Figures of Lines subtest prominent differences were found in flexibility and originality measures, while in the fluency measure there were only marginal differences in favor of bilinguals. In the elaboration measure bilingual children did not differ from their monolingual coevals. Thus, performance of bilinguals and monolinguals on Figural TTST test is varied in accordance with definite subtests; however, the differences between the groups receive full expression only in total measures. 


\subsubsection{PMS Task}

The children's answers in both groups were identical in nature. On average, participants offered between 3 and 6 solutions (Table 3, Fluency), and their answers were sufficiently varied. The most common solution was to use an object on which the kitten could climb in order to reach its cap (e.g., " climb on the chair, table, bench etc"). Most often these were the objects represented in the picture: the chair, the stool, and the bedside table. In some cases the children suggested the use of a ladder ("climb on a ladder") or of some other object that wasn't presented in the picture ("refrigerator, bed, case, etc"). Another relatively frequent solution was to ask for the help of adults (parents, relatives etc.). Other solutions such as "climb on a rope" and "to fly up" were rare.

Overall, the two groups achieved similar results on the PSM task. The findings presented in Table 3 show that there were no statistically significant distinctions between monolingual and bilingual children in any of the creativity measures. Even so, note that monolinguals demonstrated higher mean scores than bilinguals.

Table 3. Children's performance on PMST and CEN tasks ( $M$ and $S D$ )

\begin{tabular}{lcccc}
\hline & Monolinguals & Bilinguals & $p$ & $\eta^{2}$ \\
\hline PMST & & & & \\
Fluency & $5.4(1.6)$ & $5.0(1.4)$ & .480 & .018 \\
Flexibility & $37.6(13.4)$ & $32.9(12.9)$ & .340 & .033 \\
Originality & $28.1(13.7)$ & $21.4(10.6)$ & .148 & .073 \\
Creativity & $1217(9)$ & 891.7 & .230 & .051 \\
CEN & & &. & \\
Fluency & $6.8(3.1)$ & $8.6(3.1)$ & .120 & .084 \\
Flexibility & $33.9(3.7)$ & $47.9(4.8)$ & $.014^{*}$ & .200 \\
Originality & $9.1(8.4)$ & $21.7(13.2)$ & $.005^{* *}$ & .258 \\
Creativity & $55.1(62.5)$ & $184.5(125.2)$ & $.002^{* *}$ & .315 \\
\hline
\end{tabular}

${ }^{*} p \leq .05, * * p \leq .01$

\subsubsection{CEN Task}

Both monolingual and bilingual children coped rather well with the CEN task. The most frequent solutions were: (a) to transfer two bottle caps (at times one by one) from the group of 7 to the group of 3 (for a result of 5-5), (b) to transfer two caps from the group of 7 to the group of 3 and afterwards to remove 1 cap from each of the two equal groups (4-4), (c) the same as (b) but removing two caps from each group (3-3), and (d) removing all caps and afterwards using two of them (1-1). Thus, the children chose the four solutions that were most obvious from the quantitative point of view and at the same time relatively simple. They resorted mostly to a two-step method that had not been considered by the authors of the test (Tsamir et al., 2009): step 1 - method $b$ (removing four elements from the set of seven), and step 2 - method $d$ (removing a number of elements from both sets in order to obtain the same number of caps in each set). Occasionally the children arranged, one after another, several variants of a solution: 4-4, 3-3, 2-2, 1-1. In this case, the first solution received the highest score, 10 (on flexibility), and the others only 0.1 . At the same time, from the point of view of originality all these solutions should received a low score of 0.1 . But there were other solutions and strategies as well, for example, the solution of $0-0$. This was not only extremely rare but also original, and consequently was awarded the highest score for originality and flexibility. The following solutions were equally original: (a) five groups of 2 caps (arranged vertically so that at each horizontal level there were only two sets (2-2); (b) two groups of 4 caps formed by addition: "Two caps and two more caps make four caps." Both monolingual and bilingual children tended to use two- and three-stage strategies for problem solving (e.g., collecting all caps, and then removing caps from one group in order to create equal groups).

The results obtained on the CEN task (Table 3) show considerable differences between bilingual and monolingual children on all creativity measures except fluency. Children in both groups produced a nearly identical number of solutions, but bilingual children were characterized by higher flexibility and originality.

Finally, a Pearson correlation analysis showed no significant correlations between the creativity measures of the three experimental tasks: TTCT, PMS, and CEN tests. 


\section{Discussion}

The present study aimed to examine two main hypotheses concerning the relationship between bilingualism and creativity: 1) bilingual children will show higher creative ability than their monolingual peers; and 2) bilingualism affects differently various domains of creative ability. The findings of the study largely confirm both hypotheses.

The results (Tables 2 and 3 for details) show that bilingual children performed better on two out of three types of creativity examined in this study: figurative creativity (examined with TTCT) and mathematical creativity (examined with the CEN task). At the same time there were no differences between bilingual and monolingual children's creativity in everyday problem solving (exhibited in performance on the PMS task). Performance on the TTCT demonstrated that while bilingual students achieved significantly higher total scores in fluency, flexibility and originality, they were notably superior to monolinguals (in fluency, flexibility and originality) only in the repeated figures of lines subtest. Accordingly, consistent with findings of previous research (M. Leikin, 2013) the present study demonstrates that relationships between creativity components and bilingualism are task-dependent, and when differences between bilingual and monolingual children are revealed, they are in favor of bilinguals.

Differences between various domains of creativity have already been widely discussed in the literature (Kozhevnikov, Kozhevnikov, Chen \& Blazhenkova, 2013; Sawyer, 2006; Simonton, 2008). Additionally, a certain discrepancy in the performance of bilinguals on different types of creativity tasks (e.g., language and figurative creativity) has been found in some studies in the field (Kharkhurin, 2010b, 2012; M. Leikin, 2013; Simonton, 2008, Cummins, 2000). Accordingly, the results of the present study are not only in line with literature data but also significantly highlight specific previous findings. We found a definite discrepancy not only in bilingual and monolingual children's performance on different creativity tests but also on subtests of the same tests. The results show that only one (out of three) TTST subtest clearly distinguishes between bilingual and monolingual participants. Moreover, there was no correlation between the results obtained on the various creativity tasks. Thus, our data clearly confirm the hypothesis that bilingualism affects differently different types of creativity as well as its different aspects (Adi-Japha et al., 2010; M. Leikin, 2013; Simonton, 2008). In other words, bilinguals' advantages in creative ability are specific rather than general.

In this regard the developmental aspect of creative ability has to be considered, too. Note that unlike the present research, in M. Leikin's previous study (2013) in which participants were 4-year-old children, significant differences between bilingual and monolingual preschoolers on the PMS task were found, too. As children in these two studies differed only in age we can draw an additional conclusion that creativity in problem solving develops with age, although differently for different domains of creativity. If in the solving of situational problems (PMS task) differences between bilingual and monolingual preschoolers disappeared with age, the opposite was found on the CEN task (mathematical creativity) in which differences only increased with age, in favor of bilingual children (cf. M. Leikin, 2013). Thus, our findings demonstrate a discrepancy between different domains of creativity while specifying the developmental nature of the children's creative ability.

High scores in flexibility and originality are commonly thought to indicate high creative ability (Kim, 2008; Runco \& Okuda, 1991; Torrance, 1974). Flexibility scores are also important for the predictive validity of divergent thinking tests (Hommel et al., 2011; Runco \& Okuda, 1991). Some scholars (Groborz \& Necka, 2003; Hommel et al., 2011) noted that creativity and divergent thinking are closely associated with cognitive control. However, according to a growing consensus, learning more than one language leads to a stronger, more selective focus on cognitive control, which is manifest in a benefit in divergent thinking and creativity (Dietrich, 2004; Hommel et al., 2011). Hommel et al. (2011) suggested that a cognitive control state provides a minimum of top-down bias and local competition, which leads to high flexibility in terms of being able to provide many different solutions to the same problem (R. Leikin 2009, 2013; Rodriguez-Fornells, De Diego Balaguer, \& Münte, 2006). Thus, a large repertoire in problem solving (flexibility measure) is an indication of highly developed divergent thinking. By contrast, the originality measure, on both the TTST subtest and the CEN test, seems to be associated with convergent thinking, enabling participants to find new and unique solutions to the same problem (Guilford, 1967; Hommel at al., 2011; R. Leikin, 2013; Torrance, 1974). Unlike divergent thinking, convergent thinking seems to benefit from strong top-down bias and strong local competition (e.g., Hommel at al., 2011). In the present study, bilingual children appeared to be well developed in both aspects of creativity and demonstrated high scores both on the flexibility and the originality measures, both in figurative and mathematical creativity). Note, however, that probably such a cognitive advantage of bilinguals is characteristic only among young balanced bilinguals (cf. Hommel at al., 2011) as well as only on certain creativity tasks. That is, such balanced development of flexibility and originality aspects of creativity has a specific rather than a general character. 


\section{References}

Adesope, O.O., Lavin, T., Thompson, T., \& Ungerleider, C. (2010). A systematic review and meta-analysis of the cognitive correlates of bilingualism. Review of Educational Research, 80(2), 207-245. http://dx.doi.org/10.3102/0034654310368803

Adi-Japha, E., Berberich-Artzi, J., \& Libnawi, A. (2010). Cognitive flexibility in drawings of bilingual children. Child Development, 81(5), 1356-1366. http://dx.doi.org/10.1111/j.1467-8624.2010.01477.x

Barron, F., \& Harrington, D.M. (1981). Creativity, Intelligence, and Personality. Annual Review of Psychology, 32, 439-476. http://dx.doi.org/10.1146/annurev.ps.32.020181.002255

Bialystok, E. (2009). Bilingualism: The good, the bad, and the indifferent. Bilingualism: Language and Cognition, 12 (1), 3-11. http://dx.doi.org/10.1017/S1366728908003477

Cummins, J. (1976). The Influence of Bilingualism on Cognitive Growth: A Synthesis of Research Findings and Explanatory Hypotheses. Working Papers on Bilingualism, 9, 1-44.

Cummins, J. (2000). Language, Power, and Pedagogy: Bilingual Children in the Crossfire. Clevedon: Multilingual Matters.

Dietrich, A. (2004). The cognitive neuroscience of creativity. Psychonomic Bulletin \& Review, 11, 1011-1026. http://dx.doi.org/10.3758/BF03196731

Groborz, M. \& Necka, N. (2003). Creativity and cognitive control: Explorations of generation and evaluation Skills. Creativity Research Journal, 15(2 \& 3), 183-197. http://dx.doi.org/10.1080/10400419.2003.9651411

Guilford, J. P. (1967). The Nature of Human Intelligence. New York: McGraw-Hill.

Hakuta, K. (1986). Mirror of Language: The Debate on Bilingualism. NY: Basic Books.

Heilman, K.M. (2005). Creativity and the Brain. New York and Hove: Psychology Press.

Hommel, B., Colzato, L. S., Fischer, R., \& Christoffels, L. K. (2011). Bilingualism and creativity: benefits in convergent thinking come with losses in divergent thinking. Frontiers in Psychology, 2(273), 1-5.

Kessler, C., \& Quinn, M. E. (1987). Language minority children's linguistic and cognitive creativity. Journal of Multilingual and Multicultural Development, 8, 173-186. http://dx.doi.org/10.1080/01434632.1987.9994284

Kharkhurin, A. V. (2012). Multilingualism and Creativity. Bristol: Multilingual Materials.

Kharkhurin, A. V. (2010a). Sociocultural differences in the relationship between bilingualism and creativity potential. Journal of Cross-Cultural Psychology, 41 (5-6), 776-783. http://dx.doi.org/10.1177/0022022110361777

Kharkhurin, A. V. (2010b). Bilingual verbal and nonverbal creative behavior. International Journal of Bilingualism. 14(2), 211-226. http://dx.doi.org/10.1177/1367006910363060

Kim, K. H. (2008). Meta-analyses of the relationship of creative achievement to both IQ and divergent thinking test scores. The Journal of Creative Behavior, 42(2), 106-130. http://dx.doi.org/10.1002/j.2162-6057.2008.tb01290.x

Kozhevnikov, M., Kozhevnikov, M., Chen Jiao Yu \& Blazhenkova, O. (2013). Creativity, visualization abilities, and visual cognitive style. British Journal of Educational Psychology, 83, 196-209. http://dx.doi.org/10.1111/bjep.12013

Kroll, J. F., Dussias, P. E., Bogulski, C. A., \& Valdes-Kroff, J. (2012). Juggling two languages in one mind: What bilinguals tell us about language processing and its consequences for cognition. In B. Ross (Ed.), The Psychology of Learning and Motivation, Volume 56 (pp. 229-262). San Diego: Academic Press.

Kushnir, H. (1999). I Have a Problem. Notebook for creative thinking development. Publication: AHY Jerusalem 91164 (In Hebrew).

Leikin R. (2009). Exploring mathematical creativity using multiple solution tasks. In R. Leikin, A. Berman and B. Koichu (eds.), Creativity in Mathematics and the Education of Gifted Students (129-145). Rotterdam: Sense Publishers.

Leikin R. (2013). Evaluating mathematical creativity: The interplay between multiplicity and insight. Psychological Test and Assessment Modeling, 55(4), 385-400. 
Leikin, M. \& Tovli, E. (In press). The Effect of Bilingualism on Various Types of Creativity in Early Childhood. Creativity Research Journal.

Leikin, M. (2013). The Effect of bilingualism on creativity: Developmental and educational perspectives. International Journal of Bilingualism, 6, 1-17.

Prior, A. \& MacWhinney, B. (2010). A bilingual advantage in task switching. Bilingualism: Language and Cognition 13 (2), 253-262. http://dx.doi.org/10.1017/S1366728909990526

Ricciardelli, L. A. (1992a). Bilingualism and cognitive development in relation to threshold theory. Journal of Psycholinguistic Research, 21 (4), 301-316. http://dx.doi.org/10.1007/BF01067515

Ricciardelli, L. A. (1992b). Bilingualism and cognitive development: A review of past and recent findings. Journal of Creative Behavior, 26, 242-254. http://dx.doi.org/10.1002/j.2162-6057.1992.tb01183.x

Rodriguez-Fornells, A., De Diego Balaguer, R., \& Münte, T. F. (2006). Executive control in bilingual language processing. Language Learning, 56(1), 133-190. http://dx.doi.org/10.1111/j.1467-9922.2006.00359.x

Runco, M. A. \& Okuda, S. M. (1991). The instructional enhancement of the flexibility and originality scores of divergent thinking tests. Applied Cognitive Psychology, 5(5), 435-441. http://dx.doi.org/10.1002/acp.2350050505

Runko, M. A. (2008). Commentary: Divergent thinking is not synonymous with creativity. Psychology of Aesthetics, Creativity, and the Arts, 2(2), 93-96. http://dx.doi.org/10.1037/1931-3896.2.2.93

Saul, M. \& Leikin, R. (2010). Intercultural aspects of creativity: Challenges and barriers. Mediterranean Journal for Research in Mathematics Education. 9, 1-9.

Sawyer, R.K. (2006). Exploring Creativity. Oxford: Oxford University Press.

Simonton, D. K. (2000). Creativity: Cognitive, developmental, personal, and social aspects. American Psychologist, 55, 151-158. http://dx.doi.org/10.1037/0003-066X.55.1.151

Simonton, D. K. (2008). Bilingualism and creativity. In J. Altarriba \& R.R. Heredia (Eds.), An Introduction to Bilingualism: Principles and Processes (pp. 147-166). Mahwah, NJ: Lawrence Erlbaum.

Torrance, E.P. (1974). Torrance Tests of Creative Thinking: Directions Manual and Scoring Guide. Lexington, MA: Ginn.

Tsamir P., Tirosh D., Tabach M., \& Levenson E. (2009). Multiple solution methods and multiple outcomes - is it a task for kindergarten children? Educational Studies in Mathematics, 73(3), 217-231. http://dx.doi.org/10.1007/s10649-009-9215-z 
Appendix 1

Pictorial Multiple Solution Task

(Borrowed from Kushnir's "I have a problem" notebook (1999)

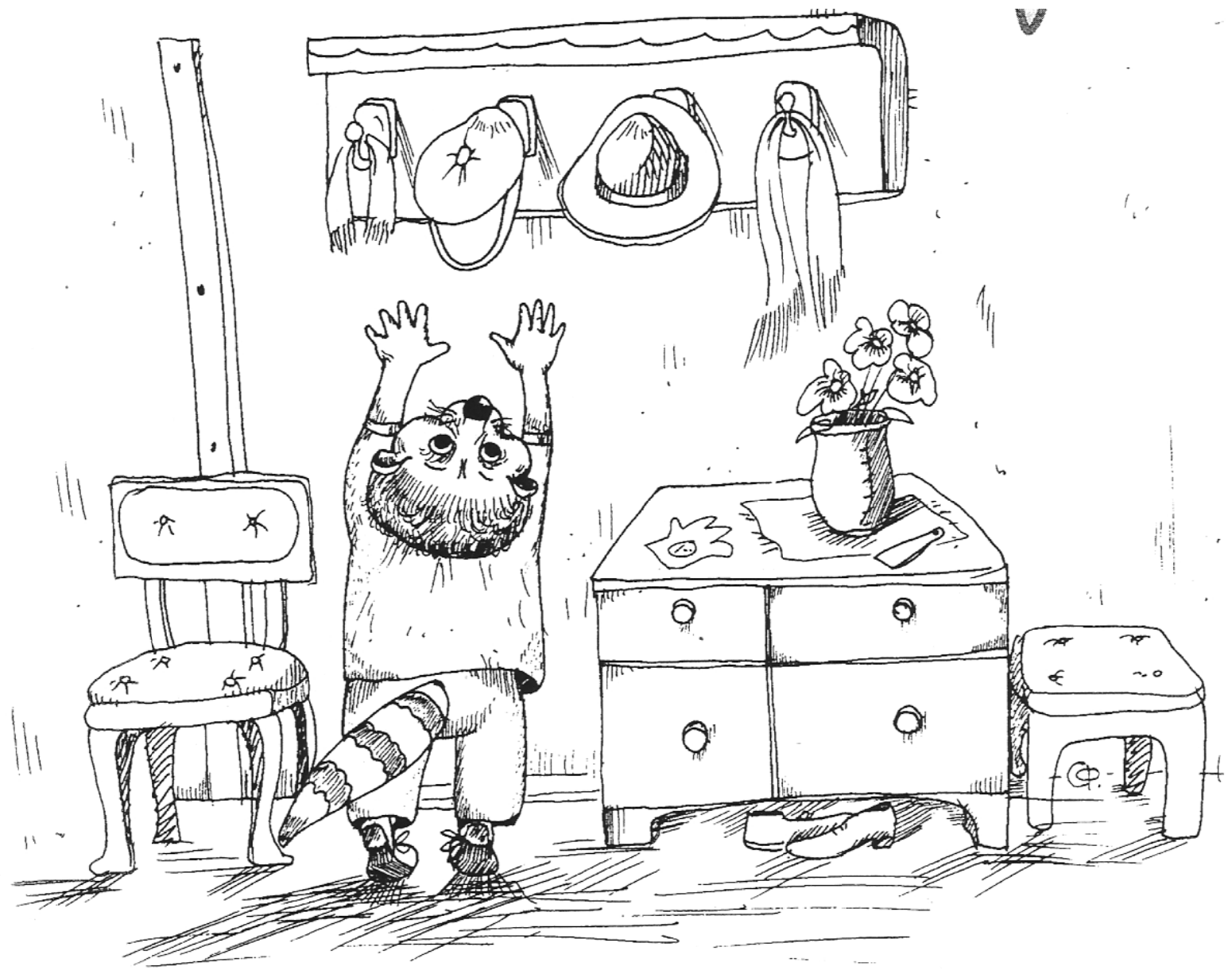

